\title{
Do subterranean mammals use the Earth's magnetic field as a heading indicator to dig straight tunnels?
}

\author{
Sandra Malewski ${ }^{\text {Corresp.., }}{ }^{1}$, Sabine Begall ${ }^{1,2}$, Cristian E. Schleich ${ }^{3}$, Carlos D. Antenucci $^{3}$, Hynek Burda ${ }^{1,2}$ \\ 1 Department of General Zoology, University of Duisburg-Essen, Essen, Germany \\ 2 Department of Game Management and Wildlife Biology, Czech University of Agriculture, Prague, Czech Republic \\ 3 Laboratorio de Ecología Fisiológica y del Comportamiento, Instituto de Investigaciones Marinas y Costeras (IIMyC), Consejo Nacional de Investigaciones \\ Científicas y Técnicas (CONICET), Universidad Nacional de Mar del Plata, Mar del Plata, Buenos Aires, Argentina \\ Corresponding Author: Sandra Malewski \\ Email address: sandra.malewski@uni-due.de
}

Subterranean rodents are able to dig long straight tunnels. Keeping the course of such 'runways' is important in the context of optimal foraging strategies and natal or mating dispersal. These tunnels are built in the course of a long time, and in social species, by several animals. Although the ability to keep the course of digging has already been described in the 1950s, its proximate mechanism could still not be satisfactorily explained. Here, we analyzed the directional orientation of 68 burrow systems in five subterranean rodent species (Fukomys anselli, F. mechowii, Heliophobius argenteocinereus, Spalax galili, and Ctenomys talarum) on the base of detailed maps of burrow systems charted within the framework of other studies and provided to us. The directional orientation of the vast majority of all evaluated burrow systems on the individual level (94\%) showed a significant deviation from a random distribution. The second order statistics (averaging mean vectors of all the studied burrow systems of a respective species) revealed significant deviations from random distribution with a prevalence of north-south (Heliophobius argenteocinereus), NNW-SSE (Ctenomys talarum), and NE-SW (Fukomys mole-rats) oriented tunnels. Burrow systems of Spalax galili were randomly oriented. We suggest that the Earth's magnetic field acts as a common heading indicator, facilitating to keep the course of digging. This study provides a field test and further evidence for magnetoreception and its biological meaning in subterranean mammals. Furthermore, it lays the foundation for future field experiments. 


\section{Do subterranean mammals use the Earth's magnetic field as a heading}

\section{2 indicator to dig straight tunnels?}

3

4 Sandra Malewski ${ }^{1}$, Sabine Begall ${ }^{1,3}$, Cristian E. Schleich ${ }^{2}$, Carlos D. Antenucci ${ }^{2 *}$, Hynek

5 Burda $^{1,3}$

6

7 'Department of General Zoology, University of Duisburg-Essen, Essen, Germany

$8 \quad{ }^{2}$ Laboratorio de Ecología Fisiológica y del Comportamiento, Instituto de Investigaciones

9 Marinas y Costeras (IIMyC), Consejo Nacional de Investigaciones Científicas y Técnicas

10 (CONICET), Universidad Nacional de Mar del Plata, Mar del Plata, Buenos Aires, Argentina

$11{ }^{3}$ Department of Game Management and Wildlife Biology, Czech University of Agriculture,

12 Prague, Czech Republic

13

$14 *$ Note that the author changed his name from 'Antinuchi' to 'Antenucci'. 


\section{Abstract}

Subterranean rodents are able to dig long straight tunnels. Keeping the course of such 'runways' is important in the context of optimal foraging strategies and natal or mating dispersal. These tunnels are built in the course of several weeks to years, and, in social species, by several animals. Although the ability to keep the course of digging was described in the 1950s, its proximate mechanism could still not be satisfactorily explained. Here, we analyzed the directional orientation of 68 burrow systems in five subterranean rodent species (Fukomys anselli, F. mechowii, Heliophobius argenteocinereus, Spalax galili, and Ctenomys talarum) on the base of detailed maps of burrow systems charted within the framework of other studies and provided to us. The directional orientation of the vast majority (94\%) of all evaluated burrow systems on the individual level showed a significant deviation from a random distribution. The second order statistics (averaging mean vectors of all the studied burrow systems of a respective genus or species) revealed significant deviations from random distribution with a prevalence of north-south (Heliophobius argenteocinereus), NNW-SSE (Ctenomys talarum), and NE-SW (Fukomys mole-rats) oriented tunnels. Burrow systems of Spalax galili were randomly oriented.

41 We suggest that the Earth's magnetic field acts as a common heading indicator, facilitating to 42 keep the course of digging. This study provides a field test and further evidence for magnetoreception and its biological meaning in subterranean mammals. Furthermore, it lays the foundation for future field experiments.

\section{Introduction}


47 Across the globe, about 250 rodent species, belonging to different unrelated taxa (six families, 38

48

49 genera), have convergently adapted to permanent life in self-excavated extensive underground burrow systems (for review see Begall et al., 2007, Lacey, 2000, Nevo, 1999). Burrow systems inhabited by single individuals (solitary species) or families (social species) can reach lengths of several hundred meters or, in social species, even kilometers (Brett, 1991, Šklíba et al., 2012, Šumbera et al., 2003, Šumbera et al., 2012, Šumbera et al., 2008). Here, the animals live, communicate, orientate in space and time in a dark, monotonous sensory environment free of most orientation cues which are available aboveground. Especially light propagation is highly limited in subterranean burrow systems, so that vision is of little use for subterranean rodents there (Kott et al., 2014). Since environmental cues are mostly lacking in the subterranean ecotope, rodents are forced to rely on idiothetic cues to orientate which are, however, prone to accumulations of errors. Consequently, an external reference that could be used for orientation and navigation would be of high value (Moritz et al., 2007). While the question, how these animals can orientate in their complex underground maze, has been repeatedly addressed (Burda, 1987, Eloff, 1951, Kimchi et al., 2004, Kimchi and Terkel, 2001), one interesting sensory ecological aspect remained understudied. How do subterranean mammals manage to keep the course of digging? This question was first raised approximately 70 years ago in 1951 when Eloff mentioned the 'remarkable ability [of the South-African Cryptomys mole-rat] to follow a direction or find a spot where it previously bored a tunnel' (Eloff, 1951, p. 145). The African mole-rat's ability to maintain its course while digging long, straight tunnels (Eloff, 1951) gave rise to speculations on possible orientation cues: air currents (de Graaff, 1972, Eloff, 1958, Poduschka, 1978) and acoustic cues (Eloff, 1951, Müller and Burda, 1989, Rosevear, 1969) have been discussed, as well as internal mechanisms based on kinesthetic and/or vestibular cues 
70 (Teroni et al., 1988). However, none of these mechanisms provide a satisfactory explanation for

71 the highly efficient directional orientation observed in Cryptomys hottentotus (Eloff, 1951). Inspired by the mentioned enigmatic ability, about 40 years after Eloff, Burda (Burda, 1987) postulated that the mole-rats might use magnetic cues to orientate and navigate, an ability which was then explicitly proven in the laboratory repeatedly, specifically for the Zambian Ansell's mole-rat (Fukomys anselli, formerly assumed to represent the same species as the South African Cryptomys hottentotus and in papers published before 2006 named so) (Burda, 1987, Burda et al., 1990, Malewski et al., 2018, Marhold, 1997, Thalau et al., 2006, Wegner et al., 2006). The phenomenon of magnetoreception, meaning an animal's sensory ability to extract information from the Earth's magnetic field, has been investigated since the 1960s (for review see Begall et al., 2014, Wiltschko and Wiltschko, 1995). However, studies with the purpose to unravel the function of the mammalian magnetic sense are still rare (Holland et al., 2006, Kimchi et al., 2004). Following the finding that African mole-rats are magnetosensitive (Burda et al. 1990), Lovegrove et al. (1992) investigated directional orientation of burrow systems of Damaraland mole-rats (Fukomys damarensis) in the field, inferring that the 'orientation of the burrow system with respect to a specific compass orientation may represent an intrinsic requirement of successful geomagnetic orientation and direction finding' (Lovegrove et al., 1992, p. 631). However, no correlation between the Earth's magnetic field and the burrow system's orientation was found. Years later, Schleich and Antinuchi (2004) performed a comparable study on burrow systems of Talas tuco-tucos (Ctenomys talarum), and achieved also negative results. However, in both studies, the data were analyzed by means of a $\mathrm{Chi}^{2}$-test, which does not take the specific characteristics of circular data into account (e.g. $10^{\circ}$ is close to $350^{\circ}$ ), and which is therefore less powerful than circular statistics. Furthermore, the previously used 
93 'polygon method' expressed directional alignment of the burrow system through a line

94 connecting the most distant points of a polygon surrounding the burrow system. Since this

95 method ignores all the shorter side branches of a burrow system within the circumferential

96 polygon, a new, more detailed and accurate method would be of avail.

In our study, we revive the question raised by Eloff (1951), and test if subterranean

rodents use the Earth's magnetic field as a heading indicator to keep a straight course of digging. Keeping a digging direction, for example during foraging (Burda, 1987) or during natal or mating dispersal (Hickman, 1990, Nevo, 1999, Rado et al., 1992) would be advantageous, as digging curvy tunnels would imply increased or even devastating energetic costs; note that costs for digging are between 360 and up to 3,400 times higher than if the animal moves the same distance above ground (Vleck, 1979). We may assume that straight tunnels longer than e.g. one meter are not the product of a single digging bout, and in the case of social species, not even of a single individual (Jarvis et al., 1994). This fact points out the necessity of a heading indicator to keep the course of digging. While diverse heading indicators (visual or olfactory landmarks, sun position, wind direction) can be used to keep the course of locomotion aboveground, availability of such cues is restricted underground.

To test the hypothesis of a magnetic heading indicator, we analyzed the directional orientation of complete burrow systems excavated in the field of five subterranean rodent species, three of which are already known to be magnetosensitive (Oliveriusová et al., 2012): two Fukomys mole-rat species (Fukomys anselli and Fukomys mechowii), the silvery mole-rat (Heliophobius argenteocinereus), the blind mole rat (Spalax galili), and the Talas tuco-tuco (Ctenomys talarum) by means of two different methods. 


\section{Material and Methods}

117 Our dataset consisted of 68 burrow systems of five subterranean rodent species (Fukomys anselli,

118 Fukomys mechowii, Heliophobius argenteocinereus, Ctenomys talarum, Spalax galili),

119 belonging to three non-related families with different geographic distribution, and representing

120 both solitary or social lifestyles (Table 1). All burrow systems were mapped within the

121 framework of previous field ecological studies (Lövy et al., 2015, Schleich and Antinuchi, 2004,

122 Šklíba et al., 2012, Šklíba et al., 2010, Šklíba et al., 2009, Šumbera et al., 2003, Šumbera et al.,

123 2012, Šumbera et al., 2008), and the maps were provided to us for this study. They were

124 digitized true to scale by means of Guantum GIS (QGIS Geographic Information System,

www.qgis.osgeo.org) for burrow systems of silvery mole-rats, Fukomys mole-rats, and Spalax,

126 and by means of ImageJ (Schneider et al., 2012) for burrow systems of Talas tuco-tucos. We

127 pooled the data of both species of Fukomys mole-rats in order to increase the sample size. It

128 should be noted that both species are phylogenetically related, live in the same habitat in the

129 same geographic region and have the same lifestyle. The direction of magnetic North was noted

130 as accompanying information as usual in geographical mapping. The data has been collected

131 blindly with respect to the analysis of compass directionality, since the original purpose of the

132 excavation was not to study burrow orientation, but to obtain data about other aspects of

133 subterranean life (e.g. burrow architecture). In our study, the systems were digitally analyzed

134 twice, by applying two different methods: the 'polygon method', which was applied already in

135 previous studies (Lovegrove et al., 1992, Schleich and Antinuchi, 2004), and the 'long tunnel

136 method', introduced by us here (Figure S1). Since the animals' original digging direction

137 (unidirectional) cannot be deduced from the excavations or drawings, bidirectional analysis was

138 the method of choice, i.e., data are doubled (modulo 360) before being analyzed, and the 
139 resulting mean vector is then back-converted, thus ranging in the interval $\left(0^{\circ} ; 180^{\circ}\right)$. All axial

140 values are reported as $\mathrm{XX}^{\circ} / \mathrm{XX}^{\circ}(\mathrm{N} / \mathrm{S})$.

141

142 Table 1: Tested rodent species (sorted alphabetically by their common names). Additionally,

143 number of mapped burrow systems, locality and year of excavation, rodent family, lifestyle, and

144 references to the studies describing burrow architecture of the respective species are listed.

146 The 'polygon method' (Figure S1 (A), (C)) is based on drawing a convex polygon

147 connecting the outermost points of a burrow system. A diagonal, marking the longest distance

148 within the polygon, was drawn, representing the main axis of the burrow system. The direction

149 of the longest distance within the polygon was measured blindly (i.e. without knowing the

150 direction of magnetic North) by means of a digital compass rose. Subsequently, all measured

151 values were unblinded by normalizing the data relative to the direction of true magnetic North.

152 The 'long tunnel method' (Figure S1 (B), (E)) weights the magnetic axial direction of the

153 branches within a burrow system depending on their length. The underlying hypothesis

154 concerning this approach was the following: The longer the distance, which was dug in a specific

155 magnetic direction, the stronger is the animal's preference for that particular direction. To apply

156 this method, first, we determined the directions of all straight tunnels of a burrow system blindly

157 (i. e. the evaluator did not know the direction of magnetic North). We defined a 'straight tunnel'

158 as straight segment including small turns/curves which ended at a clear change in direction of

159 more than $30^{\circ}$ (see Figure S1 (E)). Only straight tunnels that were at least as long as $5 \%$ of the

160 polygon's length surrounding the whole system were included in our data set. The tunnels' axial

161 directions were measured by means of a digital compass rose. After unblinding the data, vector 
162 analysis of each straight tunnel direction weighted by the tunnels' lengths was performed to

163 calculate the mean direction for each burrow system separately. Therefore, the vector's direction

164 was treated as value and its length as frequency (see frequency editor of Oriana 4.0, Kovach

165 computing systems).

166 All drawings of polygons and diagonals as well as their evaluations were performed with Fiji

167 (Schindelin et al., 2012). Circular statistics (Batschelet, 1981) and vector analyses were

168 calculated by using Oriana 4.0 (Kovach computing systems). Axial mean values were calculated

169 for each species and each method (for the 'long tunnel method', the mean vector (grand mean)

170 was calculated over the mean axial directions of the respective tunnels). The Rayleigh-test of

171 uniformity was used to test for significant deviations from a random distribution. Watson-

172 Williams F-test (pairwise comparison) was applied to compare the burrow systems' directions

173 achieved by both methods for each species, respectively.

\section{Results}

By applying the 'long tunnel method', the axial orientation of the vast majority of all evaluated burrow systems (94\%) showed a significant deviation from a random distribution, i. e. in 64 out of the 68 analyzed tunnel systems the straight tunnel segments were oriented significantly in a certain axial compass direction (Fukomys: $100 \%$; H. argenteocinereus: $90 \%$; C. talarum: $95 \%$;

S. galili: $100 \%$ ). Considering the second order statistics (averaging the mean vectors of all analyzed burrow systems of a respective genus or species), a significant deviation from random orientation was found for the Fukomys mole-rats, the silvery mole-rat, and the Talas tuco-tuco 
185 rats showed a preference for the NE/SW. No prevailing magnetic direction of the studied

186 burrows was found in the blind mole rat (S. galili) (Figure 1). whether the tunnel systems' lengths and locality of excavation (Blantyre, Mpalaganga, Mulanje; random orientation was found for systems which were shorter than $100 \mathrm{~m}\left(\mathrm{~N}=15, \mu=1 / 181^{\circ}\right.$, $\mathrm{SD}=31^{\circ}, \mathrm{P}=0.007$; mean length $=57 \mathrm{~m}, \mathrm{SD}=26 \mathrm{~m}$ ), in contrast to systems which were longer than $100 \mathrm{~m}\left(\mathrm{~N}=16, \mu=15 / 195^{\circ}, \mathrm{SD}=48^{\circ}, \mathrm{P}=0.406\right.$; mean length $\left.=192 \mathrm{~m}, \mathrm{SD}=68 \mathrm{~m}\right)$. With respect to the locality of excavation, a significant deviation from random orientation was only observable in one out of three localities (Blantyre: $\mathrm{N}=17, \mu=5 / 185^{\circ}, \mathrm{SD}=34^{\circ}, \mathrm{P}=0.015$; Mpalaganga: $\mathrm{N}=10, \mu=169 / 349^{\circ}, \mathrm{SD}=52^{\circ}, \mathrm{P}=0.702$; Mulanje: $\mathrm{N}=4, \mu=20 / 200^{\circ}, \mathrm{SD}=30^{\circ}$, $\mathrm{P}=0.272$ ). Furthermore, we did not find statistical sex-dependent differences in mean orientation for any of the solitary species (statistics not shown). The 'polygon method' revealed that the alignment of the burrow systems of the Talas tuco-tuco deviated significantly from random orientation (Figure 1 B, F). A similar strong tendency was observable for the silvery mole-rat's systems (Figure $1 \mathrm{~A}, \mathrm{E})$. The burrow systems of the Fukomys mole-rats (Figure $1 \mathrm{C}, \mathrm{G})$ and the blind mole rat (Figure $1 \mathrm{D}, \mathrm{H}$ ) showed random directional orientation. method' (Figure 1 A-D) and the prevailing direction of the burrows estimated by the 'long tunnel method' (Figure 1 E-H) did not differ significantly except for the Fukomys mole-rats (WatsonWilliams F-test (pairwise comparisons for each species): Fukomys mole-rats: $\mathrm{p}=0.042$, silvery mole-rat: $p=0.423$, tuco-tuco: $p=0.455$, blind mole rat: $p=0.636)$, however, a greater scatter was observable by applying the 'polygon method'. 


\section{Discussion}

210 Figure 1 illustrates that the 'polygon method' provides less consistent results than the 'long

211 tunnel method'. Since the 'polygon method' has been employed in previous studies (Lovegrove

212 et al., 1992, Schleich and Antinuchi, 2004), we decided to use this method and present its results

213 for the sake of comparability, too. However, the 'polygon method' is generally suitable only for

214 rather linear instead of circular burrow systems, where the long diagonal within a polygon

215 represents the directional alignment of the whole burrow system. In a more circular system,

216 several diagonals of similar lengths can be drawn (Figure S1 (D)). Various ecological factors

217 influence the geometry of a burrow system. Radiality (high branching) of a burrow system is

218 expected to increase with uniformity and predictability of food resources, age of the burrow

219 system, and with the number of inhabitants (Romañach et al., 2005, Sichilima et al., 2008,

220 Thomas et al., 2016). Moreover, the architecture of burrow systems can vary seasonally and in

221 dependence on the inhabitant's sex (e.g. dispersing and mate-seeking individuals might build

222 more linear tunnels) (Antinuchi and Busch, 1992, Nevo, 1999, Šklíba et al., 2012, Šumbera et al.,

223 2003, Šumbera et al., 2012, Šumbera et al., 2008). Indeed, the index of circularity (formula: $4 \pi$

224 (area) $/$ perimeter $^{2}, 0=$ linear, $1=$ circular; Romañach et al., 2005) identifies $60 \%$ of the studied

225 burrow systems of the solitary silvery mole-rats (Figure $2 \mathrm{~A}$ ) and $70 \%$ of the systems of the

226 solitary tuco-tucos as being rather linear (with an index $<0.7$ as exemplarily defined threshold

227 separating the upper third as being circular), while all systems of the social Fukomys mole-rats

228 exhibited values $>0.7$ (Figure $2 B$ ).

229 In contrast to the 'polygon method', the 'long tunnel method' revealed constant results 230 for different species independent from the respective indices of circularity. Having applied this 
231 method, we found a significant deviation from random axial orientation for burrowing longer

232 straight tunnels along a certain axis, which was specific for each burrow system. Moreover, the

233 second order statistics (averaging mean vectors of all burrow systems of a respective genus or

234 species) revealed significant deviation from random orientation in all the tested species but

235 Spalax galili (Figure 1), including a prevalence of NNW/SSE in case of Talas tuco-tucos and

236 NE-SW in case of Fukomys mole-rats. The fact that the studied burrow systems have been

237 uncovered in different regions (even continents) and areas (e.g. grassland, woodland,

238 mountainous areas), and thus accompanying different habitats, as well as in different years

239 (1998-2012; Table 1), support the assumption that the Earth's magnetic field seems to be a

240 globally common and stable potential heading indicator. Accordingly, we suggest that the

241 studied species use magnetic cues as heading indicator to keep the course of digging. This

242 hypothesis does not exclude that the animals use also further, locally available heading

243 indicators, for this purpose. Indeed, magnetoreception has been proved in the laboratory for $F$.

244 anselli (Burda et al., 1990, Marhold et al., 1997), F. mechowii (Oliveriusová et al., 2012), and $H$.

245 argenteocinereus (Oliveriusová et al., 2012). Interestingly, magnetoreception was not proved in

246 laboratory maze experiments in C. talarum (Schleich and Antinuchi, 2004), which, however,

247 could have been due to an inappropriate experimental design as discussed by the authors

248 themselves (Schleich and Antinuchi, 2004). On the other hand, magnetoreception has been

249 proven in Spalax judaei (Kimchi and Terkel, 2001, Marhold et al., 2000), a close relative of $S$.

250 galili for which no directional preference for digging was found here. The reasons, why no

251 directional digging preference was found in S. galili, can be manifold. All analyzed burrow

252 systems originate from a single small area in the Upper Galilee Mountains, and six of nine

253 examined burrow systems were located in basaltic soils. Basaltic soils are generally 
254 characterized by rather strong magnetic signatures and the studied region is known for magnetic

255 anomalies (Eppelbaum et al., 2004) that might compromise magnetic orientation. Furthermore,

256 the population density in basaltic soil is five times higher than in rendzina soil (Lövy et al.,

257 2015). The avoidance of crossing a neighboring burrow system might influence the burrow

258 systems orientation and thus possibly override orientation via magnetic cues. Therefore, it is of

259 great interest to analyze comparative data on directionality of burrow systems of Spalax from

260 other geographic regions and other habitats (cf., Nevo et al., 1995, Reyes et al., 2003, Savić,

261 1973, Yağci et al., 2010).

262

The burrow systems of Heliophobius analyzed here $(N=31)$ were excavated at three

different localities, characterized by different landscapes (Blantyre, N=17: grassland;

264 Mpalaganga, $\mathrm{N}=10$ : woodland; Mulanje, $\mathrm{N}=4$ : mountainous) and thus habitats. A significant

265 deviation from random axial orientation was only observable for the systems from Blantyre. The

266 larger scatter of mean vectors at Mulanje might be partially explained by the lower sample size.

267 Secondly, at Mpalaganga and Mulanje, several systems were excavated in cultivated areas,

268 where higher density and uniformity of food resources might have had influenced foraging

269 strategies and thus also the burrow architecture. Another factor, which seems to affect the burrow

270 system's orientation of silvery mole-rats is the system's length - while shorter systems $(<100 \mathrm{~m})$

271 were oriented significantly in North-South direction (every other direction would have been

272 equally plausible), longer systems (>100 m) were not. This is, however, not surprising,

273 considering that the larger a system becomes, the stronger an original alignment might be

274 overridden or masked. Trying to explain these findings, we have to consider that a system's size

275 presumably grows with its age. Consequently, a system's axial orientation may rather be

276 observable when it is shorter (in statu nascendi) compared to when it is longer and older. 
278 follow every direction, and indeed, species-specific differences in chosen nest-building

279 directions were already reported repeatedly (for review see Oliveriusová et al., 2012). However,

280 the North-South axis might be the direction of choice. A preference for this axis, as observed in

281 our study for silvery mole-rats and Talas tuco-tucos, is common in studies on magnetic

282 orientation (e.g. Malkemper et al., 2015, Oliveriusová et al., 2014, Phillips, 1986) and magnetic

283 alignment (for review see Begall et al., 2013, Malkemper et al., 2016), and is observable in

284 diverse contexts: landing in waterfowl (Hart et al., 2013), escape in roe deer (Obleser et al.,

285 2016), activity in cattle and deer (Begall et al., 2008), flamingos (Nováková et al., 2017), corvids

286 (Pleskač et al., 2017), wild boars and warthogs (Červený et al., 2017), carps (Hart et al., 2012).

287 Considering that species-specific burrowing behavior in North American Peromyscus rodents

288 was reported to have a genetic basis (Dawson et al., 1988, Hu and Hoekstra, 2017, Metz et al.,

289 2017, Weber et al., 2013), we would like to point to the possibility that 'magnetic digging' might

290 be genetically determined, too, representing a highly interesting research question.

291 Since magnetic and further orientation cues are not exclusive, apart from the Earth's

292 magnetic field, several other cues might influence the alignment of the burrow systems. The

293 most crucial external cues might be food resources (e.g. Heth et al., 2002, Romañach et al.,

294 2005), soil condition (implying the presence of stones and other obstacles) (e.g. Ebensperger and

295 Bozinovic, 2000, Kimchi et al., 2005, Luna et al., 2002, Zuri and Terkel, 1997), and landscape

296 characteristics (e.g. dunes, vegetation, slopes, water currents), and even subsurface geological

297 fractures might function as orientation cues (Olson and Pollard, 1989). Presence of food

298 resources influences goal-directed burrowing at shorter distances (Eloff, 1951, Voigt, 2014).

299 Since geophytes are usually clumped, and can be located at a limited distance by smelling plant 
300 kairomones diffused in the soil (Heth et al., 2002, Lange et al., 2005), an optimal foraging

301 strategy is expected to involve digging straight scouting tunnels with perpendicular shorter

302 branches in fertile areas (following kairomone cues). Although season is expected to affect the

303 digging activity (Sichilima et al., 2008) and general architecture of the burrow system (Šumbera

304 et al., 2003), it is highly unlikely that its main orientation, if present, changes seasonally,

305 wherefore we do not assume significant seasonal influences.

306

307 Conclusion and outlook

308 To conclude, the Fukomys mole-rats, the silvery mole-rat, as well as the Talas tuco-tuco were

309 shown to dig their burrow systems with respect to a certain axis, and are assumed to use the

310 Earth's magnetic field as a possible heading indicator. In future studies, animals might be

311 released at a new site so that the genesis of the new burrow system might be monitored in situ as

312 for example done by Voigt et al. (2014). Furthermore, digging experiments should be performed

313 under controlled laboratory conditions to unequivocally experimentally demonstrate that

314 subterranean rodents use magnetic cues to keep a heading direction during digging.

315

316 Acknowledgements

317 We thank R. Šmbera and M. Lövy for providing most of the data and for their helpful

318 comments on the manuscript. Further thanks are due to J. Šklíba for offering digital maps of

319 tunnel systems of the Ansell's mole-rats, W. N. Chitaukali, V. Dvořáková, M. Elichová, E.

320 Hrouzková, H. Konvičková, O. Kott, J. Kubová, V. Mazoch, J. Ritter as well as all local helpers

321 who assisted in the field, and N. Oberste for assistance with the analyses. 


\section{Data accessibility}

324 The dataset supporting this article will be made accessible via university homepage upon

325

326

327

328

329

330

331

332

333

334

335

336

337

338

339

340

341

342

343

344

345

346

347

348

349

350

351

352

353

354

355

356

357

358

359

360

361

362

acceptance of the manuscript.

\section{References}

ANTINUCHI, C. D. \& BUSCH, C. 1992. Burrow structure in the subterranean rodent Ctenomys talarum. Zeitschrift für Säugetierkunde, 57, 163-168.

BATSCHELET, E. 1981. Circular Statistics in Biology, New York, Academic Press. 371 pp.

BEGALL, S., BURDA, H. \& MALKEMPER, E. P. 2014. Magnetoreception in mammals. Advances in the Study of Behavior, 46, 45-88. DOI 10.1016/B978-0-12-800286-5.00002-X.

BEGALL, S., BURDA, H. \& SCHLEICH, C. E. (eds.) 2007. Subterranean Rodents - News from Underground, Berlin, Heidelberg, New York: Springer. 398 pp. DOI 10.1007/978-3-540-69276-8.

BEGALL, S., ČERVENÝ, J., NEEF, J., VOJTĔCH, O. \& BURDA, H. 2008. Magnetic alignment in grazing and resting cattle and deer. Proceedings of the National Academy of Sciences of the United States of America, 105, 13451-13455. DOI 10.1073/pnas.0803650105.

BEGALL, S., MALKEMPER, E. P., ČERVENÝ, J., NĚMEC, P. \& BURDA, H. 2013. Magnetic alignment in mammals and other animals. Mammalian Biology, 78, 10-20. DOI 10.1016/j.mambio.2012.05.005.

BRETT, R. A. 1991. The ecology of naked mole-rat colonies: burrowing, food, and limiting factors. In: SHERMAN, P. W., JARVIS, J. U. M. \& D., A. R. (eds.) The Biology of the Naked Mole-rat. Princeton, New Jersey: Princeton University Press. 137-184. DOI 10.1515/9781400887132-008.

BURDA, H. 1987. Magnetische Navigation bei den Graumullen, Cryptomys hottentotus (Bathyergidae)? Zeitschrift für Säugetierkunde, (Suppl. 61), 12.

BURDA, H., MARHOLD, S., WESTENBERGER, T., WILTSCHKO, R. \& WILTSCHKO, W. 1990. Magnetic compass orientation in the subterranean rodent Cryptomys hottentotus (Bathyergidae). Experientia, 46, 528-530. DOI 10.1007/bf01954256.

ČERVENÝ, J., BURDA, H., JEŽEK, M., KUŠTA, T., HUSINEC, V., NOVÁKOVÁ, P., HART, V., HARTOVÁ, V., BEGALL, S. \& MALKEMPER, E. P. 2017. Magnetic alignment in warthogs Phacochoerus africanus and wild boars Sus scrofa. Mammal Review, 47, 1-5. DOI 10.1111/mam.12077.

DAWSON, W. D., LAKE, C. E. \& SCHUMPERT, S. S. 1988. Inheritance of burrow building in Peromyscus. Behavior Genetics, 18, 371-382. DOI 10.1007/bf01260937.

DE GRAAFF, G. 1972. On the mole-rat (Cryptomys hottentotus damarensis) (Rodentia) in the Kalahari Gemsbok National Park. Koedoe, 15, 25-35. DOI 10.4102/koedoe.v15i1.665.

EBENSPERGER, L. A. \& BOZINOVIC, F. 2000. Energetics and burrowing behaviour in the semifossorial degu Octodon degus (Rodentia : Octodontidae). Journal of Zoology, 252, 179-186. DOI 10.1111/j.14697998.2000.tb00613.x.

ELOFF, G. 1951. Orientation in the mole-rat Cryptomys. British Journal of Psychology, 42, 134-145. DOI 10.1111/j.2044-8295.1951.tb00285.x. 
401

402

403

404

405

406

407

408

ELOFF, G. 1958. The functional and structural degeneration of the eye of the South African rodent moles, Cryptomys bigalkei and Bathyergus maritimus. South African Journal of Science, 293-302.

EPPELBAUM, L., BEN-AVRAHAM, Z. \& KATZ, Y. 2004. Integrated analysis of magnetic, paleomagnetic and $\mathrm{K}-\mathrm{Ar}$ data in a tectonic complex region: an example from the Sea of Galilee. Geophysical Research Letters, 31, L19602. DOI 10.1029/2004gl021298.

HART, V., KUŠTA, T., NĚMEC, P., BLÁHOVÁ, V., JEŽEK, M., NOVÁKOVÁ, P., BEGALL, S., ČERVENÝ, J., HANZAL, V., MALKEMPER, E. P., ŠTÍPEK, K., VOLE, C. \& BURDA, H. 2012. Magnetic alignment in carps: evidence from the Czech christmas fish market. PLOS ONE, 7(12), e51100. DOI 10.1371/journal.pone.0051100.

HART, V., MALKEMPER, E. P., KUŠTA, T., BEGALL, S., NOVÁKOVÁ, P., HANZAL, V., PLESKAČ, L., JEŽEK, M., POLICHT, R., HUSINEC, V., ČERVENÝ, J. \& BURDA, H. 2013. Directional compass preference for landing in water birds. Frontiers in Zoology, 10(1), 38. DOI 10.1186/1742-9994-10-38.

HETH, G., TODRANK, J., BEGALL, S., KOCH, R., ZILBIGER, Y., NEVO, E., BRAUDE, S. H. \& BURDA, H. 2002. Odours underground: subterranean rodents may not forage "blindly". Behavioral Ecology and Sociobiology, 52, 53-58. DOI 10.1007/s00265-002-0476-0.

HICKMAN, G. C. 1990. Adaptiveness of tunnel systems features in subterranean mammal burrows. In: NEVO, E. \& REIG, O. A. (eds.) Evolution of Subterranean Mammals at the Organismal and Molecular Levels. New York: Wiley-Liss. 185-210.

HOLLAND, R. A., THORUP, K., VONHOF, M. J., COCHRAN, W. W. \& WIKELSKI, M. 2006. Navigation - Bat orientation using Earth's magnetic field. Nature, 444, 702. DOI 10.1038/444702a.

HU, C. K. \& HOEKSTRA, H. E. 2017. Peromyscus burrowing: a model system for behavioral evolution. Seminars in Cell \& Developmental Biology, 61, 107-114. DOI 10.1016/j.semcdb.2016.08.001.

JARVIS, J. U. M., O'RIAIN, M. J., BENNETT, N. C. \& SHERMAN, P. W. 1994. Mammalian eusociality - a family affair. Trends in Ecology \& Evolution, 9, 47-51. DOI 10.1016/0169-5347(94)90267-4.

KIMCHI, T., ETIENNE, A. S. \& TERKEL, J. 2004. A subterranean mammal uses the magnetic compass for path integration. Proceedings of the National Academy of Sciences of the United States of America, 101, 1105-1109. DOI 10.1073/pnas.0307560100.

KIMCHI, T., RESHEF, M. \& TERKEL, J. 2005. Evidence for the use of reflected self-generated seismic waves for spatial orientation in a blind subterranean mammal. Journal of Experimental Biology, 208, 973973. DOI 10.1242/jeb.01396.

KIMCHI, T. \& TERKEL, J. 2001. Magnetic compass orientation in the blind mole rat Spalax ehrenbergi. Journal of Experimental Biology, 204, 751-758.

KOTT, O., MORITZ, R. E., ŠUMBERA, R., BURDA, H. \& NĚMEC, P. 2010. Light propagation in burrows of subterranean rodents: tunnel system architecture but not photoreceptor sensitivity limits light sensation range. Journal of Zoology, 294, 68-76. DOI 10.1111/jzo.12152.

LACEY, E. A. 2000. Spatial and social systems of subterranean rodents. In: LACEY, E. A., PATTON, J. L. \& CAMERON, G. N. (eds.) Life Underground: the Biology of Subterranean Rodents. Chicago and London: University of Chicago Press. 257-293.

LANGE, S., NEUMANN, B., HAGEMEYER, P. \& BURDA, H. 2005. Kairomone-guided food location in subterranean Zambian mole-rats (Cryptomys spp., Bathyergidae). Folia Zoologica, 54, 263-268.

LOVEGROVE, B. G., KÖRTNER, G. \& KÖRTNER, G. 1992. The magnetic compass orientation of the burrows of the Damara mole-rat Cryptomys damarensis (Bathyergidae). Journal of Zoology, 226, 631-633. DOI 10.1111/j.1469-7998.1992.tb07505.x.

LÖVY, M., ŠKLIIBA, J., HROUZKOVÁ, E., DVOŘÁKOVÁ, V., NEVO, E. \& ŠUMBERA, R. 2015. Habitat and burrow system characteristics of the blind mole rat Spalax galili in an area of supposed sympatric speciation. PLOS ONE 10(7): e0133157. DOI 10.1371/journal.pone.0133157. 
409

410

411

412

413

414

415

416

417

418

419

420

421

422

423

424

425

426

427

428

429

430

431

432

433

434

435

436

437

438

439

440

441

442

443

444

445

446

447

448

449

450

451

452

453

454

455

456

LUNA, F., ANTINUCHI, C. D. \& BUSCH, C. 2002. Digging energetics in the South American rodent Ctenomys talarum (Rodentia, Ctenomyidae). Canadian Journal of Zoology, 80, 2144-2149. DOI 10.1139/z02201.

MALEWSKI, S., MALKEMPER, E. P., SEDLÁČEK, F., ŠUMBERA, R., CASPAR, K. R., BURDA, H. \& BEGALL, S. 2018. Attracted by a magnet: Exploration behaviour of rodents in the presence of magnetic objects. Behavioural Processes, 151, 11-15. DOI 10.1016/j.beproc.2018.02.023.

MALKEMPER, E. P., EDER, S. H. K., BEGALL, S., PHILLIPS, J. B., WINKLHOFER, M., HART, V. \& BURDA, H. 2015. Magnetoreception in the wood mouse (Apodemus sy/vaticus): influence of weak frequencymodulated radio frequency fields. Scientific Reports, 5 (9917). DOI 10.1038/srep09917.

MALKEMPER, E. P., PAINTER, M. S. \& LANDLER, L. 2016. Shifted magnetic alignment in vertebrates: Evidence for neural lateralization? Journal of Theoretical Biology, 399, 141-147. DOI 10.1016/j.jtbi.2016.03.040.

MARHOLD, S. 1997. Magnetic orientation in common mole-rats from Zambia. The 1997 Spring Conference of the Royal Institute Navigation, 5.1-5.9.

MARHOLD, S., BEILES, A., BURDA, H. \& NEVO, E. 2000. Spontaneous directional preference in a subterranean rodent, the blind mole-rat, Spalax ehrenbergi. Folia Zoologica, 49, 7-18.

MARHOLD, S., WILTSCHKO, W. \& BURDA, H. 1997. A magnetic polarity compass for direction finding in a subterranean mammal. Naturwissenschaften, 84, 421-423. DOI 10.1007/s001140050422.

METZ, H. C., BEDFORD, N. L., PAN, Y. L. \& HOEKSTRA, H. E. 2017. Evolution and genetics of precocious burrowing behavior in Peromyscus mice. Current Biology, 27, 3837-3845. DOI 10.1016/j.cub.2017.10.061.

MORITZ, R. E., BURDA, H., BEGALL, S. \& NĚMEC, P. 2007. Magnetic compass: a useful tool underground. In: BEGALL, S., BURDA, H. \& SCHLEICH, C. E. (eds.) 2007. Subterranean Rodents - News from Underground, Berlin, Heidelberg, New York: Springer. 161-174. DOI 10.1007/978-3-540-692768_12.

MÜLLER, M. \& BURDA, H. 1989. Restricted hearing range in a subterranean rodent, Cryptomys hottentotus. Naturwissenschaften, 76, 134-135. DOI 10.1007/bf00366611.

NEVO, E. 1999. Mosaic Evolution of Subterranean Mammals: Regression, Progression, and Global Convergence, New York, Oxford University Press. 448 pp.

NEVO, E., FILIPPUCCI, M. G., REDI, C., SIMSON, S., HETH, G. \& BEILES, A. 1995. Karyotype and genetic evolution in speciation of subterranean mole-rats of the genus Spalax in Turkey. Biological Journal of the Linnean Society, 54, 203-229. DOI 10.1111/j.1095-8312.1995.tb01034.x.

NOVÁKOVÁ, P., KOŘANOVÁ, D., BEGALL, S., MALKEMPER, E. P., PLESKAČ, L., ČAPEK, F., ČERVENÝ, J., HART, V., HARTOVÁ, V., HUSINEC, V. \& BURDA, H. 2017. Direction indicator and magnetic compass-aided tracking of the sun by flamingos? Folia Zoologica, 66, 79-86. DOI 10.25225/fozo.v66.i2.a2.2017.

OBLESER, P., HART, V., MALKEMPER, E. P., BEGALL, S., HOLÁ, M., PAINTER, M. S., ČERVENÝ, J. \& BURDA, H. 2016. Compass-controlled escape behavior in roe deer. Behavioral Ecology and Sociobiology, 70, 1345-1355. DOI 10.1007/s00265-016-2142-y.

OLIVERIUSOVÁ, L., NĚMEC, P., KRÁLOVÁ, Z. \& SEDLÁČEK, F. 2012. Magnetic compass orientation in two strictly subterranean rodents: learned or species-specific innate directional preference? Journal of Experimental Biology, 215, 3649-3654. DOI 10.1242/jeb.069625.

OLIVERIUSOVÁ, L., NĚMEC, P., PAVELKOVÁ, Z. \& SEDLÁČEK, F. 2014. Spontaneous expression of magnetic compass orientation in an epigeic rodent: the bank vole, Clethrionomys glareolus. Naturwissenschaften, 101, 557-563. DOI 10.1007/s00114-014-1192-0.

OLSON, J. \& POLLARD, D. D. 1989. Inferring paleostresses from natural fracture patterns: a new method. Geology, 17, 345-348. DOI 10.1130/0091-7613(1989)017<0345:ipfnfp>2.3.co;2.

PHILLIPS, J. B. 1986. Magnetic compass orientation in the eastern red-spotted newt (Notophthalmus viridescens). Journal of Comparative Physiology A, 158, 103-109. DOI 10.1007/bf00614524. 
457

458

459

460

461

462

463

464

465

466

467

468

469

470

471

472

473

474

475

476

477

478

479

480

481

482

483

484

485

486

487

488

489

490

491

492

493

494

495

496

497

498

499

500

501

502

503

PLESKAČ, L., HART, V., NOVÁKOVÁ, P. \& PAINTER, M. S. 2017. Spatial orientation of foraging corvids consistent with spontaneous magnetic alignment responses observed in a variety of free-roaming vertebrates. Folia Zoologica, 66, 87-94. DOI 10.25225/fozo.v66.i2.a3.2017.

PODUSCHKA, W. 1978. Abwehhrreaktionen der Mullratte, Cryptomys hottentottus (Lesson, 1826). Säugetierkundliche Mitteilungen, 26, 260-274.

RADO, R., WOLLBERG, Z. \& TERKEL, J. 1992. Dispersal of young mole rats (Spalax ehrenbergi) from the natal burrow. Journal of Mammalogy, 73, 885-890. DOI 10.2307/1382211.

REYES, A., NEVO, E. \& SACCONE, C. 2003. DNA sequence variation in the mitochondrial control region of subterranean mole rats, Spalax ehrenbergi superspecies, in Israel. Molecular Biology and Evolution, 20, 622-632. DOI 10.1093/molbev/msg061

ROMAÑACH, S. S., SEABLOOM, E. W., REICHMAN, O. J., ROGERS, W. E. \& CAMERON, G. N. 2005. Effects of species, sex, age, and habitat on geometry of pocket gopher foraging tunnels. Journal of Mammalogy, 86, 750-756. DOI 10.1644/1545-1542(2005)086[0750:eossaa]2.0.co;2.

ROSEVEAR, D. R. 1969. The Rodents of West Africa. London, United Kingdom, British Museum of Natural History. $604 \mathrm{pp}$.

SAVIĆ, I. R. 1973. Ecology of the species Spalax leucodon Nordm. in Yugoslavia. Natural Science, 44, 5-70.

SCHINDELIN, J., ARGANDA-CARRERAS, I., FRISE, E., KAYNIG, V., LONGAIR, M., PIETZSCH, T., PREIBISCH, S., RUEDEN, C., SAALFELD, S., SCHMID, B., TINEVEZ, J. Y., WHITE, D. J., HARTENSTEIN, V., ELICEIRI, K., TOMANCAK, P. \& CARDONA, A. 2012. Fiji: an open-source platform for biological-image analysis. Nature Methods, 9, 676-682. DOI 10.1038/nmeth.2019.

SCHLEICH, C. E. \& ANTINUCHI, C. D. 2004. Testing magnetic orientation in a solitary subterranean rodent Ctenomys talarum (Rodentia: Octodontidae). Ethology, 110, 485-495. DOI 10.1111/j.14390310.2004.00981.x.

SCHNEIDER, C. A., RASBAND, W. S. \& ELICEIRI, K. W. 2012. NIH Image to ImageJ: 25 years of image analysis. Nature Methods, 9, 671-675. DOI 10.1038/nmeth.2089.

SICHILIMA, A. M., BENNETT, N. C., FAULKES, C. G. \& LE COMBER, S. C. 2008. Evolution of African mole-rat sociality: burrow architecture, rainfall and foraging in colonies of the cooperatively breeding Fukomys mechowii. Journal of Zoology, 275, 276-282. DOI 10.1111/j.1469-7998.2008.00439.x.

ŠKLÍBA, J., MAZOCH, V., PATZENHAUEROVÁ, H., HROUZKOVÁ, E., LOVY, M., KOTT, O. \& ŠUMBERA, R. 2012. A maze-lover's dream: Burrow architecture, natural history and habitat characteristics of Ansell's mole-rat (Fukomys anselli). Mammalian Biology, 77, 420-427. DOI 10.1016/j.mambio.2012.06.004.

ŠKLÍBA, J., ŠUMBERA, R. \& CHITAUKALI, W. N. 2010. What determines the way of deposition of excavated soil in a subterranean rodent? Acta Theriologica, 55, 271-277. DOI 10.4098/j.at.00017051.099.2009.

ŠKLÍBA, J., ŠUMBERA, R., CHITAUKALI, W. N. \& BURDA, H. 2009. Home-range dynamics in a solitary subterranean rodent. Ethology, 115, 217-226. DOI 10.1111/j.1439-0310.2008.01604.x.

ŠUMBERA, R., BURDA, H., CHITAUKALI, W. N. \& KUBOVÁ, J. 2003. Silvery mole-rats (Heliophobius argenteocinereus, Bathyergidae) change their burrow architecture seasonally. Naturwissenschaften, 90, 370-373. DOI 10.1007/s00114-003-0439-y.

ŠUMBERA, R., MAZOCH, V., PATZENHAUEROVÁ, H., LÖVY, M., ŠKLÍBA, J., BRYJA, J. \& BURDA, H. 2012. Burrow architecture, family composition and habitat characteristics of the largest social African mole-rat: the giant mole-rat constructs really giant burrow systems. Acta Theriologica, 57, 121130. DOI 10.1007/s13364-011-0059-4.

ŠUMBERA, R., ŠKLÍBA, J., ELICHOVÁ, M., CHITAUKALI, W. N. \& BURDA, H. 2008. Natural history and burrow system architecture of the silvery mole-rat from Brachystegia woodland. Journal of Zoology, 274, 77-84. DOI 10.1111/j.1469-7998.2007.00359.x. 
504

505

506

507

508

509

510

511

512

513

514

515

516

517

518

519

520

521

522

523

524

525

526

527
TERONI, E., PORTENIER, V., MAURER, R. \& ETIENNE, A. S. 1988. The control of spatial orientation by selfgenerated and visual cues in the golden hamster. Sciences et Techniques de L'Animal de Laboratoire, 13, 99-102.

THALAU, P., RITZ, T., BURDA, H., WEGNER, R. E. \& WILTSCHKO, R. 2006. The magnetic compass mechanisms of birds and rodents are based on different physical principles. Journal of the Royal Society Interface, 3, 583-587. DOI 10.1098/rsif.2006.0130.

THOMAS, H. G., SWANEPOEL, D. \& BENNETT, N. C. 2016. Burrow architecture of the Damaraland mole-rat (Fukomys damarensis) from South Africa. African Zoology, 51, 29-36. DOI 10.1080/15627020.2015.1128355.

VLECK, D. 1979. The energy cost of burrowing by the pocket gopher Thomomys bottae. Physiological Zoology, 52, 122-136. DOI 10.1086/physzool.52.2.30152558.

VOIGT, C. 2014. An example of burrow system architecture of dispersing Damaraland mole-rats. African Zoology, 49, 148-152. DOI 10.3377/004.049.0118.

WEBER, J. N., PETERSON, B. K. \& HOEKSTRA, H. E. 2013. Discrete genetic modules are responsible for complex burrow evolution in Peromyscus mice. Nature, 493, 402-405. DOI 10.1038/nature11816.

WEGNER, R. E., BEGALL, S. \& BURDA, H. 2006. Magnetic compass in the cornea: local anaesthesia impairs orientation in a mammal. Journal of Experimental Biology, 209, 4747-4750. DOI $10.1242 /$ jeb.02573.

WILTSCHKO, R. \& WILTSCHKO, W. 1995. Magnetic orientation in animals, Berlin, Heidelberg, Springer. 297 pp. DOI 10.1007/978-3-642-79749-1.

YAĞCl, T., COŞKUN, Y. \& AŞAN, N. 2010. The tunnel structure of blind mole rats (genus Spalax) in Turkey. Zoology in the Middle East, 50, 35-40. DOI 10.1080/09397140.2010.10638409.

ZURI, I. \& TERKEL, J. 1997. Summer tunneling activity of mole rats (Spalax ehrenbergi) in a sloping field with moisture gradient. Mammalia, 61, 47-54. DOI 10.1515/mamm.1997.61.1.47. 


\section{Table $\mathbf{1}$ (on next page)}

Tested rodent species (sorted alphabetically by their common names)

Additionally, number of mapped burrow systems, locality and year of excavation, as well as references to the studies describing burrow architecture of the respective species are listed. 


\begin{tabular}{|c|c|c|c|c|c|c|}
\hline Species & Family & Social/solitary & $\begin{array}{l}\text { Number } \\
\text { of } \\
\text { burrow } \\
\text { systems }\end{array}$ & Locality & $\begin{array}{l}\text { Year of } \\
\text { excavation }\end{array}$ & $\begin{array}{l}\text { Reference, } \\
\text { burrow systems } \\
\text { were originally } \\
\text { used for }\end{array}$ \\
\hline $\begin{array}{l}\text { Ansell's mole-rat } \\
\text { (Fukomys anselli) }\end{array}$ & Bathyergidae & Social & 7 & $\begin{array}{l}\text { Lusaka East } \\
\text { Forest Reserve } \\
\text { (Zambia) }\end{array}$ & 2010 & $\begin{array}{l}\text { (Šklíba et al., } \\
\text { 2012) }\end{array}$ \\
\hline $\begin{array}{l}\text { Giant mole-rat } \\
\text { (Fukomys mechowii) }\end{array}$ & Bathyergidae & Social & 2 & $\begin{array}{l}\text { Ndola Hill } \\
\text { Forest Reserve } \\
\text { (Zambia) }\end{array}$ & 2009 & $\begin{array}{l}\text { (Šumbera et al., } \\
\text { 2012) }\end{array}$ \\
\hline $\begin{array}{l}\text { Silvery mole-rat } \\
\text { (Heliophobius } \\
\text { argenteocinereus) }\end{array}$ & Bathyergidae & Solitary & 31 & $\begin{array}{l}\text { Blantyre, } \\
\text { Mulanje, } \\
\text { Mpalaganga } \\
\text { (Malawi) }\end{array}$ & 2000,2005 & $\begin{array}{l}\text { (Šklíba et al., } \\
\text { 2010, Šklíba et al., } \\
\text { 2009, Šmbera et } \\
\text { al., 2003, Šumbera } \\
\text { et al., 2008), and } \\
\text { additional } \\
\text { previously } \\
\text { unpublished } \\
\text { burrow systems } \\
\text { (cf. raw data) }\end{array}$ \\
\hline $\begin{array}{l}\text { Talas tuco-tuco } \\
\text { (Ctenomys talarum) }\end{array}$ & Ctenomyidae & Solitary & 19 & $\begin{array}{l}\text { Mar de Cobo, } \\
\text { Buenos Aires } \\
\text { (Argentina) }\end{array}$ & 1998, 1999 & $\begin{array}{l}\text { (Schleich and } \\
\text { Antinuchi, 2004) }\end{array}$ \\
\hline $\begin{array}{l}\text { Upper Galilee } \\
\text { Mountains blind mole } \\
\text { rat } \\
\text { (Spalax galili) }\end{array}$ & Spalacidae & Solitary & 9 & $\begin{array}{l}\text { Upper Galilee } \\
\text { Mountains } \\
\text { (Israel) }\end{array}$ & 2012 & (Lövy et al., 2015) \\
\hline
\end{tabular}




\section{Figure 1}

\section{Burrow system's orientation}

Directional orientation of the burrow systems (estimated by the 'long tunnel method', A-D) and the prevailing direction of burrows (estimated by the 'polygon method', E-H) of the tested rodent species - the silvery mole-rat $H$. argenteocinereus $(A, E)$, Talas tuco-tuco $C$. talarum (B, F), Fukomys mole-rats (Ansell's mole-rat $F$. anselli and the giant mole-rat $F$. mechowii) ((C, G), and the Upper Galilee Mountains blind mole rat S. galili $(D, H)$ (sorted by sample size) - relative to magnetic North $\left(0^{\circ}\right)$. Two mirrored dots represent the axial direction of one burrow system, which is in case of the long tunnel method an axial mean vector calculated over all directions of straight tunnel segments weight by the segments' lengths. The double-headed arrow indicates the (grand) mean vector, and the inner circle marks the significance level of 0.05 (Rayleigh test). Sample size (N), mean axial direction $(\mu)$, circular standard deviation (SD) and P-value are given for each tested species. 
Long tunnel method

Polygon method

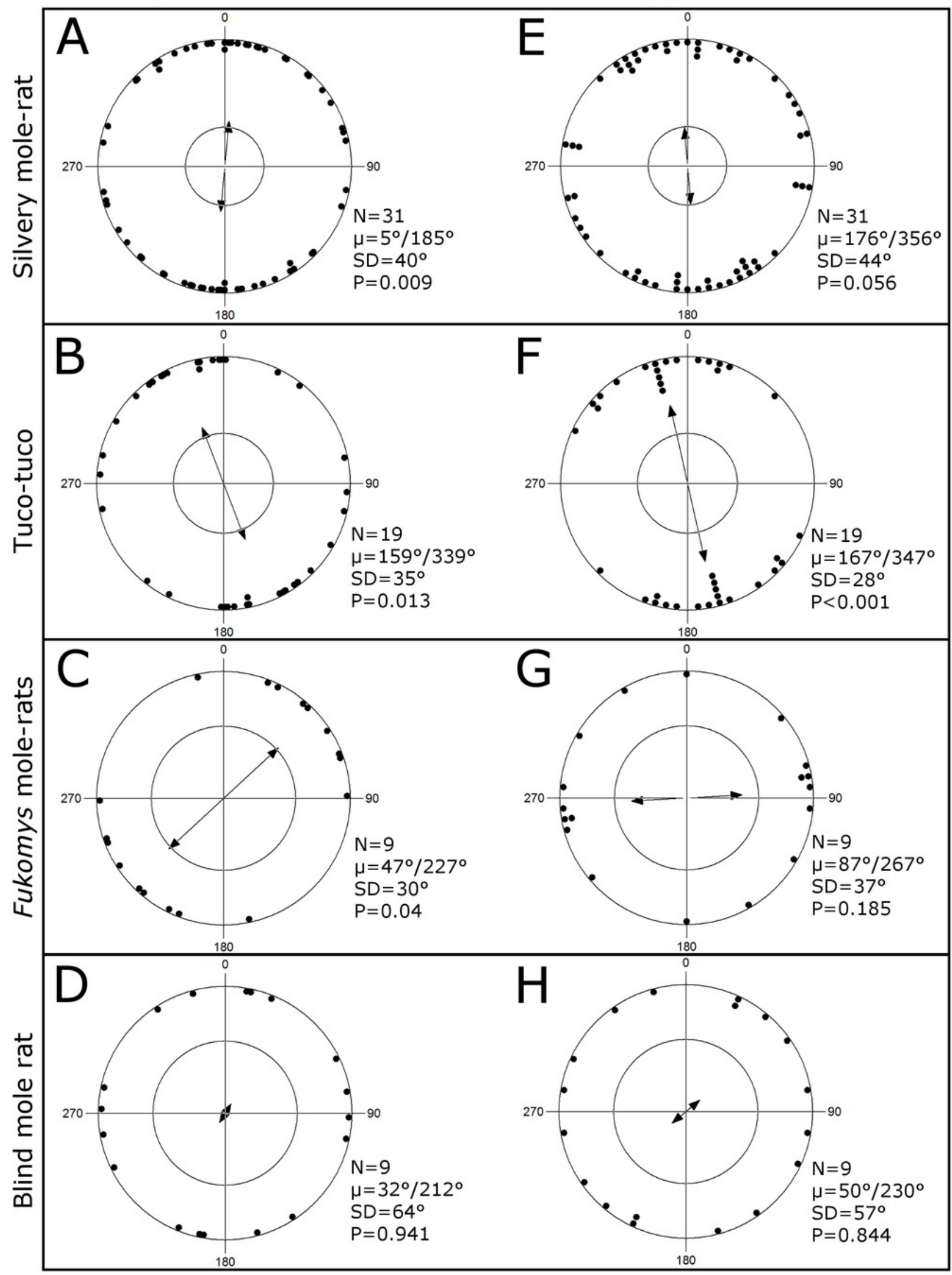


Figure 2

Examples of burrow systems of a (A) solitary (here Heliophobius argenteocinereus) and (B) social species (here Fukomys anselli).

Index of circularity $(0=$ linear, $1=$ circular; Romañach et al., 2005) for $(A)=0.42$, and $(B)=0.83$.

(A)

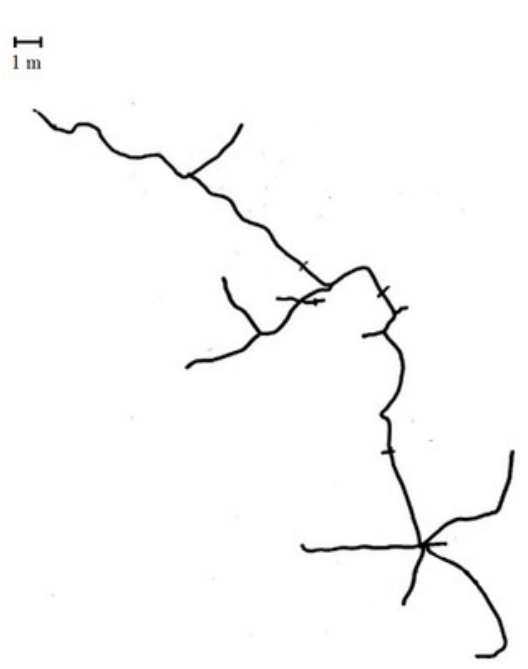

(B)
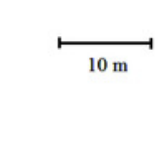

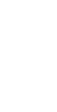

$\left(\frac{10}{20}\right.$
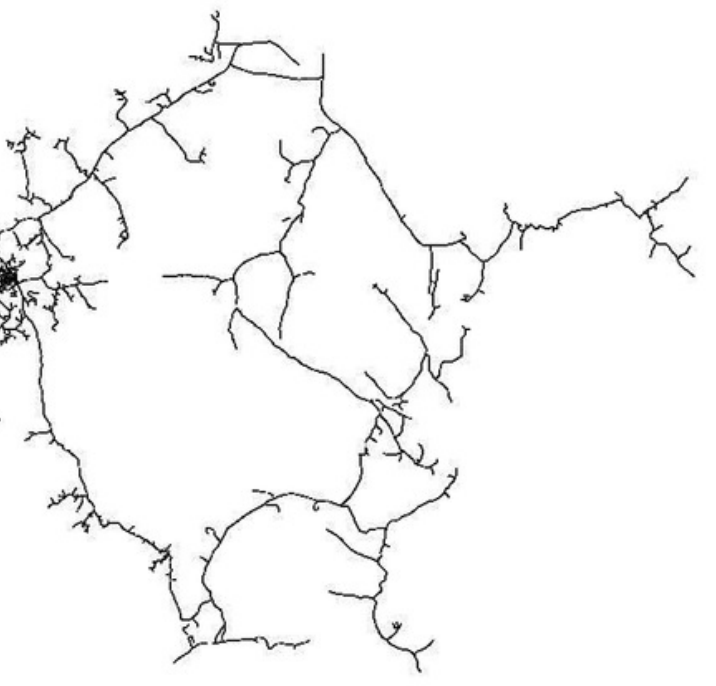